\title{
JALAN AGAR IBADAH DITERIMA
}

\author{
Rahmad Ilahi \\ Pengajar di SMP dan SMA IT Al Fath Payakumbuh, Sumatera Barat \\ Email : railabuady@gmail.com
}

\begin{abstract}
Abstrak: Sebagai seorang muslim kita meyakini bahwa kita diciptakan sebagai seorang hamba, memberikan penghambaan diri untuk Allah taala, hidup dan mati kita hanya untuk Allah taala yang bermakna semuanya harus bernilai ibadah, sebagaimana friman Allah taala:

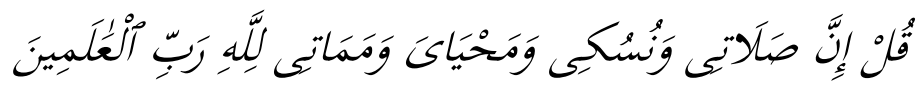

Katakanlah bahwa salatku, sembelihanku, hidup dan matiku hanya untuk Allah Rabb alam semesta. (Qs. Al Anam : 162)

Untuk menyerahkan ibadah kita kepada Allah taala, kita mesti berjalan di jalan yang Allah taala dan Rasul-Nya tetapkan, jika berjalan pada selainnya dapat dipastikan kita tersesat dalam melangkah, artinya ibadah kita salah. Agar ibadah itu menjadi ibadah yang benar, sesuai dengan kehendak Allah taala maka ada yang harus dipenuhi seorang muslim dalam melaksanakan ibadahnya, bisa kita sebut dengan syarat diterimannya ibadah yaitu memiliki ilmu tentang ibadah yang akan dikerjakannya, ilmu itu adalah mengetahuinya dengan dalil-dalil yang sahih dan harus berdasarkan penjelasan para ulama yang diakui keilmuannya, jika ia beramal tanpa ilmu ia akan mendapakan akibat buruk dari ibadah yang ia lakukan tersebut.

Setelah seorang muslim beribadah dengan ilmu, ia harus tahu penyebab ibadah itu ditunda atau ditolak oleh Allah taala, banyak hal yang menyebabkan ibadah ditolak, baik yang terlihat dari perbuatan zahir mapun yang tidak nampak dari perbuatan batin, seorang muslim yang inginkan keridhaan Allah taala, ingin mendekatkan diri kepada Allah taala dengan ibadah yang ia lakukan harus mengetahui serta menjauhi apa saja yang menjadi amalannya ditolak. Isi tulisan singkat ini adalah dua hal diatas, pertama syarat benarnya pelaksanaan sebuah ibadah dan kedua agar ibadah yang benar itu diterima disisi Allah taala.

\section{Jalan Agar Ibadah Kita Diterima Allah Taala}

Hal pertama yang harus ada dalam diri seorang muslim agar ibadahnya diterima oleh Allah taala adalah ia memiliki ilmu tentang ibadah yang ia lakukan, mengapa kita harus berilmu sebelum beramal? Dalam melakukan sesuatu kita harus tahu untuk apa kita melakukannya dan bagaimana cara melakukannya yang benar. Jangan beramal tanpa ilmu, jangan berbuat tanpa ilmu, seandainya saja kita 
membeli obat ke apotek tanpa resep dokter dan tidak tahu jenis obat yang akan kita minum, mungkin dapat menambah penyakit baru atau kita tahu obatnya tapi tidak tahu dosisnya, ini juga berbahaya.

Sebagaimana dalam kehidupan sehari-hari kita butuh ilmu, kita juga butuh ilmu dalam beragama, bahkan lebih butuh. Untuk mengendarai mobil kita harus tahu ilmu menyetir, tahu rambu-rambu lalu lintas, kalau tidak mengilmuinya boleh jadi gas kita sangka rem. Dalam beragama kita jauh lebih butuh ilmu, sebab amalan tanpa ilmu dapat merusak ibadah, bahkan bisa saja ibadah kita ditolak dan kita mendapatkan dosa, bukan pahala.

Maka yakinlah kita bahwa dalam setiap perbuatan, siapapun ia dan apapun yang dilakukannya harus paham tentang apa yang akan ia kerjakan. Jika tidak, bisa saja perbuatan yang dianggap benar adalah sebuah kesalahan.

Sehingga jelas bagi kita bahwa ilmu adalah jalan selamat atau tidaknya kita di akhirat nanti. Tujuan penciptaan kita adalah menghambakan diri atau beribadah untuk Allah taala sebagaimana firman-Nya :

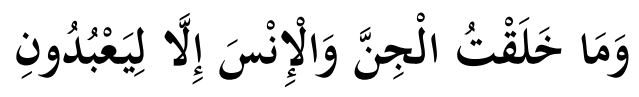

Tidaklah Aku ciptakan jin dan manusia kecuali untuk beribadah padaku (Qs. Az Zariyat : 56)

Sedangkan ibadah adalah "melakukan segala perbuatan yang disukai Allah talaa" Bagaimana agar Allah taala menyukai amalan kita? Dengan mengetahui perintah dan larangan-Nya yang tercantum dalam dalil-dalil, dalil-dalil itu dipahami dengan cara yang benar, itulah ilmu.

Apabila seorang hamba tidak memiliki ilmu dari ibadah atau amalan yang ia lakukan maka akan banyak akibat buruk dari kejahilannya itu, di antara akibat buruk itu adalah : 
Pertama, menyangka ibadah sah padahal ia tidak sah

Dalam Alquran disebutkan tentang puasa : makan dan minumlah sampai jelas bagi kalian benang putih dengan benang hitam di kala fajar. (Qs. Al Baqarah : 187).

Maka Ady bin Hatim rhadhiyallahu anhu berkata pada Rasulullah shalallahu alaihi wasallam : Wahai Rasulullah shalallahu alaihi wasallam aku meletakkan dibawah bantalku dua tali, yang satu putih dan satu lagi hitam, darinya aku dapat membedakan malam dan siang. Mendengar itu Rasulullah shalallahu alaihi wasallam menjawab :

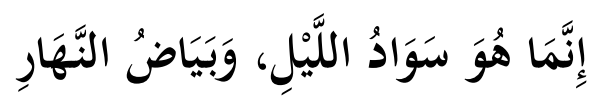

Maksudnya hitam itu kegelapan malam dan putih adalah terangnya siang. (HR. Muslim)

Dalam hadis lain disebutkan bahwa sebagian sahabat mengambil dua benang, putih dan hitam, mereka tetap makan sampai jelas benang putih dari benang hitam, jika hari terang dan sudah jelas bedanya, barulah mereka berhenti makan. Ketika mereka salah paham, turunlah ayat "minal fajr" yaitu waktu fajar.

Kita dapat melihat akibat dari kekeliruan itu, bisa saja mereka tetap makan padahal waktu sahur sudah berakhir. Jika waktu salat subuh telah masuk dan kita masih makan tentu puasa tidak sah.

Kita lihat pula dalam ibadah salat, Abu Hurairah rhadhiyallahu anhu mengatakan Rasulullah shalallahu alaihi wasallam masuk masjid, kemudian masuk pula seorang laki-laki ke dalam masjid dan ia melaksanakan salat, kemudian ia menemui Nabi shalallahu alaihi wasallam Nabi shalallahu alaihi wasallam berkata :

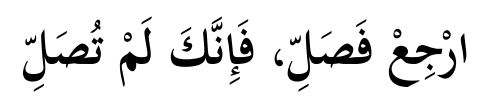

Kembalilah, sesungguhnya kamu belum salat. (HR. Bukhari dan Muslim) 
Lelaki itu kembali salat dan menemui Nabi shalallahu alaihi wasallam tapi Nabi shalallahu alaihi wasallam mengatakan hal yang sama. Akhirnya ia berkata : aku tidak tahu cara salat yang lebih baik dari yang aku lakukan tadi. Rasulullah shalallahu alaihi wasallam menjelaskan bahwa ia harus tumakninah dalam setiap gerakan salat, jika tidak ada tumakninah maka salatnya tidak sah.

Sahabat tersebut tidak mengetahui bahwa tumakninah harus ada dalam salat, ulama kita belakangan beristimbat bahwa tumakninah adalah rukun salat, siapa saja yang meninggalkannya maka salatnya tidak sah.

Kedua, menyangka ibadah batal padahal ia sah

Dalam suatu riwayat Abu Hurairah rhadhiyallahu anhu berkata :

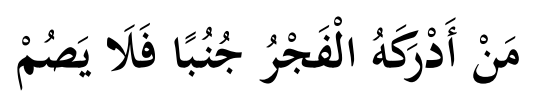

Siapa yang mendapati waktu fajar dan dia dalam keadaan junub, maka jangan puasa.

Maksud dari 'jangan puasa' adalah puasanya tidak sah, sahabat lain yang mendengar itu merasa heran, benarkah yang dikatakan Abu Hurairah rhadhiyallahu anhu tersebut? Benarkah orang yang berjunub dan masuk waktu subuh puasanya tidak sah. Maka mereka pergi menemui Aisyah rhadhiyallahu anha beliau menjawab :

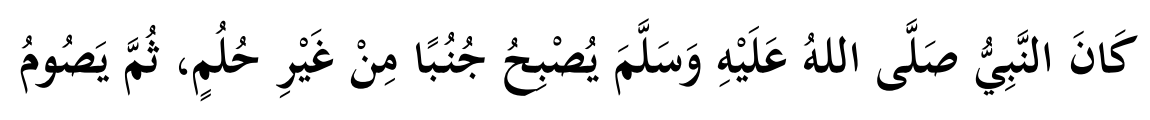

Dulu Nabi shalallahu alaihi wasallam masuk waktu subuh dan beliau dalam keadaan junub, kemudian beliau berpuasa. (HR. Muslim)

Setelah itu mereka sampaikan ke Abu Hurairah rhadhiyallahu anhu apa yang mereka dapatkan dari Aisyah rhadhiyallahu anha maka Abu Hurairah rhadhiyallahu anhu berkata : Aisyah lebih tahu dariku. 
Coba bayangkan jika pemahaman Abu Hurairah rhadhiyallahu anhu itu ada di salah seorang diantara kita, pada siang hari suami-istri haram berhubungan, kemudian malamnya ia salat Isya, dilanjutkan mendengarkan ceramah dan salat tarawih, setelah salat tarawih ia berkunjung ke rumah saudara atau temannya, kemudian pulang. Sampai di rumah sudah jam sebelas malam, kemudian dia datangi istrinya dan iapun junub. Kemudian ia tidur, jam empat ia bangun makan sahur, karena masih mengantuk dan kelelahan ia merebahkan badan, tiba-tiba terdengar suara azan dan dia belum mandi. Tentu ia akan sangat menyesal, bisa jadi besok dan seterusnya selama Ramadan ia akan menjauhi istrinya, baik siang mapun malam.

Ketiga, mempersulid yang mudah

Ammar bin Yasir rhadiyallahu anhuma memahami tayamum untuk junub dengan cara yang lain, ia berkata :

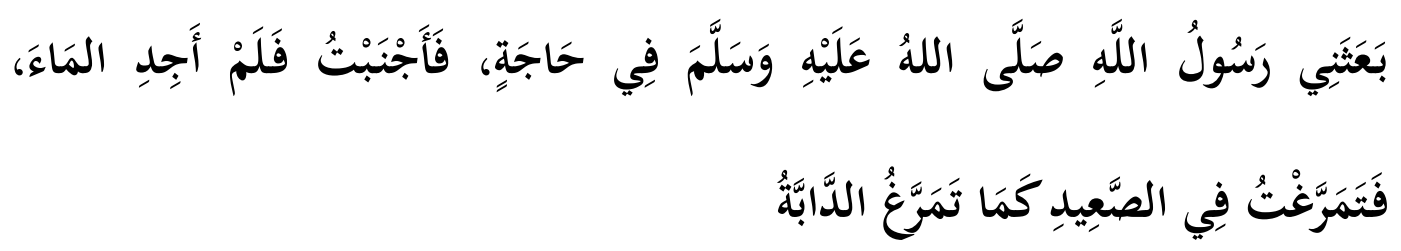

Rasulullah shalallahu alaihi wasallam mengutusku untuk suatu keperluan, akupun junub dan tidak menemukan air. Maka aku berguling-guling di tanah sebagaimana hewan berguling-guling. (HR. Bukhari dan Muslim)

Mengapa Ammar rhadhiyallahu anhu melakukan hal itu? Karena yang ia tahu ketika seseorang berjunub maka ia harus mandi, seluruh tubuhnya disiram rata dengan air. Dia juga tahu ketika tidak ada air untuk bersuci maka diganti dengan tayamum, dari situ Ammar beranggapan bahwa ia harus bertayamum dengan melumuri seluruh tubuhnya dengan tanah atau debu.

Setelah Ammar rhadhiyallahu anhu kembali ia melaporkan apa yang telah ia lakukan kepada Nabi shalallahu alaihi wasallam Nabi shalallahu alaihi wasallam menjelaskan cukup baginya untuk bertayamum seperti biasa, yaitu tayamum pengganti wudhu. Bertayamum sangat mudah sekali, tapi karena 
Ammar tidak tahu maka ia telah menyusahkan dirinya dengan berguling-guling di tanah.

Keempat, melakukan ibadah bukan pada waktunya

Saat khutbah Idul Adha Rasulullah shalallahu alaihi wasallam menyatakan bahwa berkurban itu setelah salat Id, maka Abu Burdah rhadhiyallahu anhu berkata :

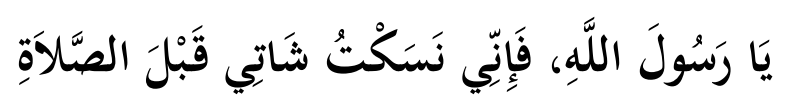

Wahai Rasulullah aku menyembelih kambingku sebelum salat.

Mengapa Abu Burdah rhadhiyallahu anhu melakukan hal itu? Karena ia ingin kambingnya yang pertama kali disembelih, ini adalah sebuah semangat dalam ibadah, tapi salah. Ia bertanya lagi kepada Rasulullah shalallahu alaihi wasallam apakah ia diberi pahala kurban atas sembelihannya?

Rasulullah shalallahu alaihi wasallam menjawab :

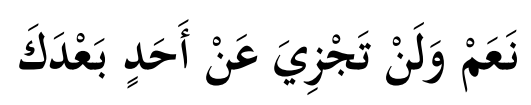

Ya, dan tidak akan dibalas seorangpun setelahmu. (HR. Bukhari dan Muslim)

Rasulullah shalallahu alaihi wasallam menegaskan lagi bahwa hewan kurban disembelih setelah salat, Abu Burdah rhadhiyallahu anhu dimaafkan, siapa saja yang menyembelih hewan kurbannya sebelum salat maka itu tidak dianggap kurban, tapi sembelihan biasa dan sedekah biasa.

Ada ibadah yang ditetapkan waktunya, ada ibadah yang ditetapkan tempatnya, jika waktunya ditukar atau tempatnya dikisar maka ibadah tersebut tidak sah. Oleh sebab itu mari kita ilmui ibadah yang kita jalankan agar diterima disisi Allah taala.

Kelima, mencelakan diri 
Jabir rhadiyallahu anhu menyatakan :
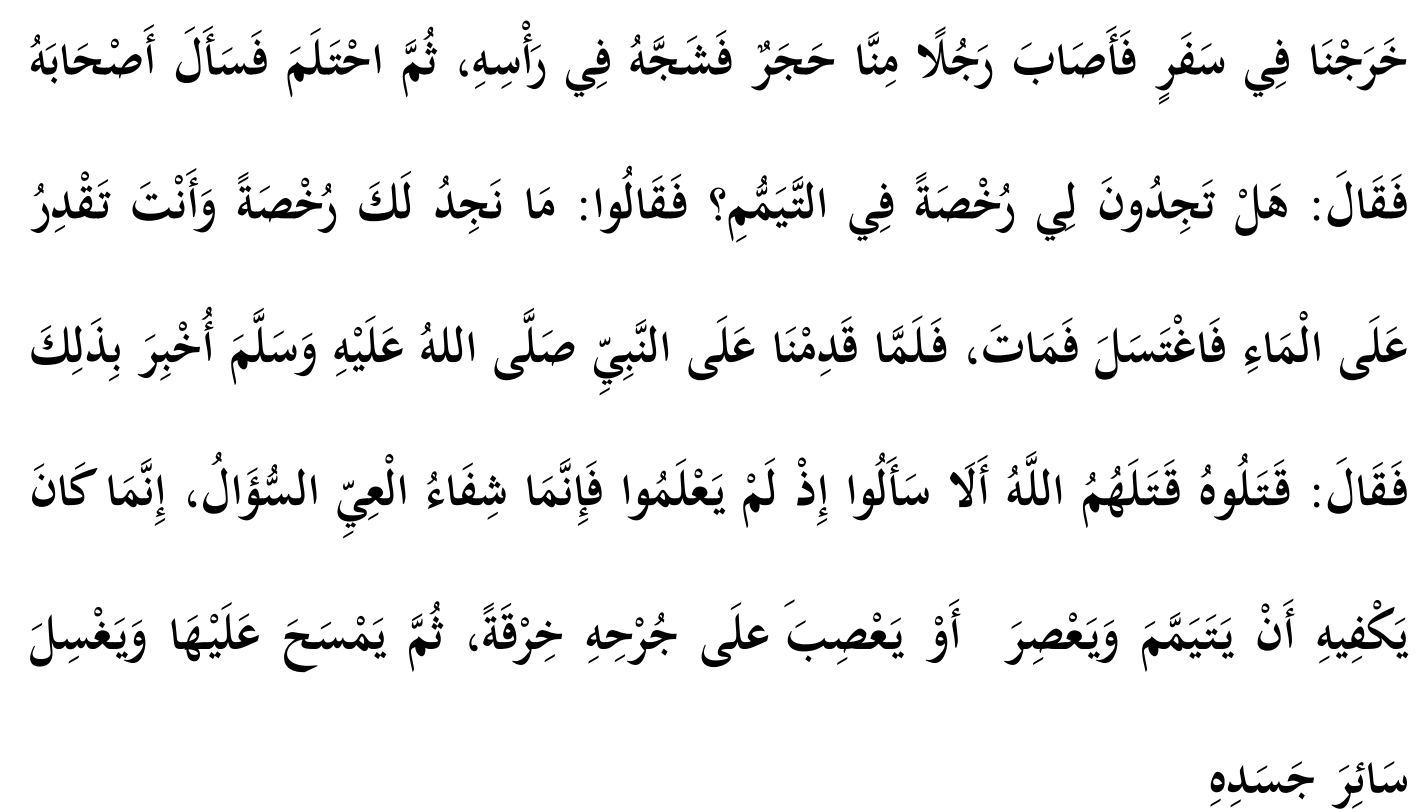

Suatu hari kami bersafar, kemudian salah seorang diantara kami ditimpa batu dan kepalanya retak, setelah itu ia mimpi basah. Ia bertanya pada temantemannya : adakah keringinan untukku agar bertayamum? Mereka menjawab : tidak ada keringanan bagimu, kamu sanggup menggunakan air. Iapun mandi wajib dan meninggal. Setelah kami menemui Nabi shalallahu alaihi wasallam dan memberitahukan hal itu, maka Rasulullah shalallahu alaihi wasallam berkata : mereka telah membunuhnya, semoga Allah binasakan mereka. Mengapa mereka tidak bertanya jika tidak tahu! Sesungguhya obat kebodohan adalah bertanya, seharusnya cukup baginya bertayamum saja dan mengikat atau membalut bagian yang luka kemudian mengusapnya, baru membasuh bagian tubuh lainnya. (HR. Abu Daud)

Mungkin banyak lagi kejadian lain yang karena tidak ada ilmunya akan membahayakan diri sendiri, sebagaimana kami pernah dengar atau baca di daerah pedalaman, sebagian umat Islam menyunat anaknya dengan memotong bagian yang cukup panjang dan itu membayakan diri yang disunat.

Pernah juga kami mendapati ada orang yang membayar zakat ke masjid, padahal masjid bukanlah para penerima zakat. Kami juga menemui orang yang 
menganggap sepupu dari jalan ayah adalah mahram karena sedarah, padahal sepupu baik dari ayah atau ibu bukanlah mahram.

Bagaimana perhatian ulama tentang berilmu sebelum beribadah? Imam Al Bukhari rahimahullah dalam kitab sahihnya membuat satu bab :

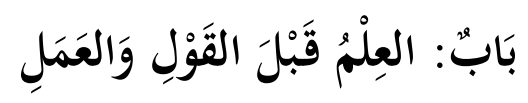

Bab : berilmu sebelum beramal.

Imam As Syatiby rahimahullah membawakan perkataan Ibn Wahb dari Sufyan rahimahullah ia berkata : Ucapan tidak akan lurus kecuali ketika ia diamalkan, ucapan dan amalan tidak akan lurus kecuali dengan keikhlasan niat. Sedangkan ucapan, amalan dan niat tidak akan lurus kecuali selaras dengan sunnah. ${ }^{1}$

Selaras dengan sunnah, artinya harus dengan ilmu, oleh karena itu mari kita belajar, mari bertanya, mari membaca, karena obat ketidaktahuan adalah belajar. Adanya ilmu sebelum beramal sangatlah penting

Dari contoh di atas kita memahami kalau ilmu tidak ada, seseorang akan salah dalam berjalan untuk mnedekatkan diri kepada Allah taala, salah memilih jalan, karena setiap kaki yang dilangkahkan dipandu oleh sangkaan, kira-kira dan kata orang, ibadah tidak berlandaskan itu semua, tapi berdasarkan kebenaran ilmiah dengan dalil dan penjelasan ahlinya, yaitu para ulama.

Apabila ilmu sudah menyertai ibadah, maka kita harus tahu pula penyebab ibadah itu dibatalkan, artinya ibadah yang seharusnya sah menjadi tidak sah karena beberapa sebab, diantaranya :

Pertama, syirik dan riya. ${ }^{1}$ Imam As Syatiby/Al I'tisham/Al Wajh Astsalis Minan Naql, Ma Jaa Anis Salaf As Shalih Minas Shahabah
Wat Tabiin Rhadiyayallahu Anhum Fi Zammil Bida' Wa Ahli Hawa Wa Huwa Katsir. 
Syirik adalah menduakan Allah taala dalam hal kekhususan Allah taala, seperti berdoa kepada roh, meminta hal gaib kepada dukun, takut pada jin dan sebagainya. Sedangkan riya memberikan sebagian atau seluruh niat dalam beribadah kepada selain Allah taala, yaitu orang yang beribadah agar dilihat orang lain.

Syirik yang kita bahas disini disebut juga dengan syirik besar, sedangkan riya dinamai syrik kecil, akhirnya keduanya adalah bentuk kesyirikan. Syirik besar membatalkan seluruh amalan, sedangkan riya membatalkan amalan yang ada riya padanya.

Tentang syirik besar Allah taaala berfirman :
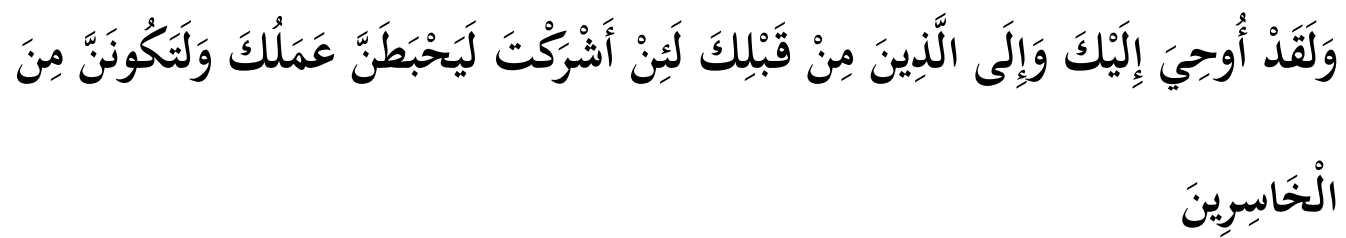

Dan sungguh telah diwahyukan kepadamu dan kepada nabi-nabi sebelummu "jika kamu berbuat syirik niscaya akan terhapuslah amalmu dan tentulah kamu termasuk orang-orang yang merugi. (Qs. Az-Zumar : 65)

Kalau amalan dibatalkan tentu tiada guna dari semua ibadah yang sudah dilaksanakan, bahkan kerugian besar akan menimpanya yaitu ditempatkan dalam neraka. Di antara bentuk kesyirikan adalah mendatangi dukun atau peramal, Beliau bersabda:

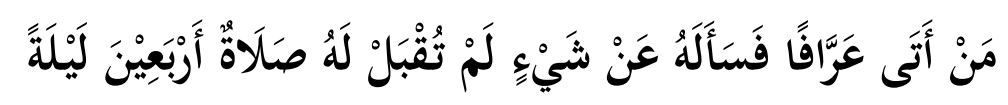

Siapa yang mendatangi peramal, kemudian dia bertanya kepadanya tentang sesuatu, maka salatnya tidak diterima selama empat puluh hari. (HR. Muslim) 
Sedangkan tentang riya Rasulullah shalallahu alaihi wasallam bersabda:

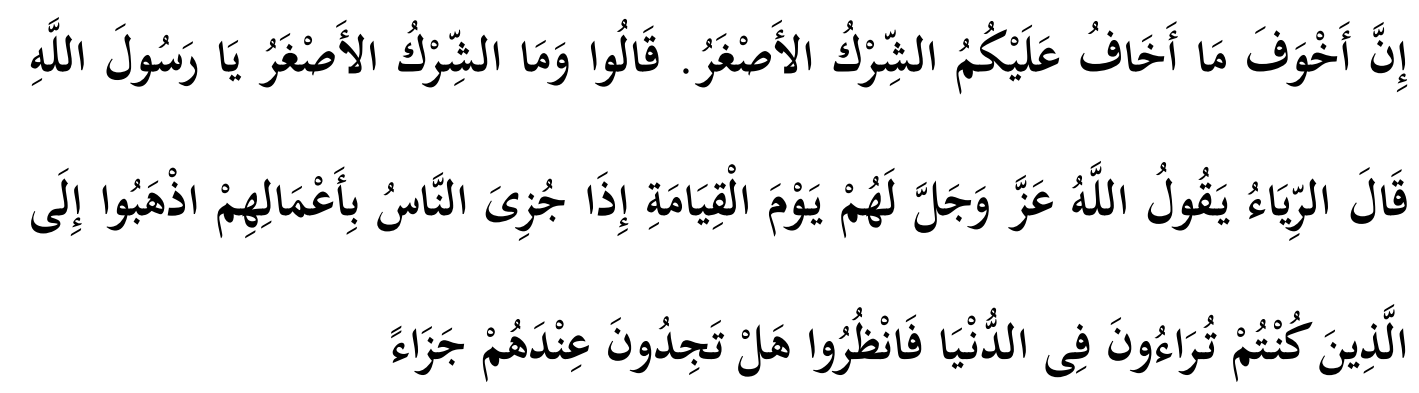

Sesungguhnya hal paling aku khawatirkan akan menimpa kalian adalah syirik kecil. Para sahabat bertanya "apa itu syirik kecil wahai Rasulullah?” Beliau bersabda "syirik kecil adalah riya. Allah Azza Wajalla berkata pada mereka yang berbuat riya pada hari kiamat ketika manusia mendapat balasan atas amalan mereka "pergilah kalian pada orang yang kalian perlihatkan ibadah kalian pada mereka di dunia. Lalu lihatlah apakah kalian mendapatkan balasan dari mereka?" (HR. Ahmad)

Allah taala menegaskan dalam Alquran tentang bahaya riya, yaitu kecelakaan yang akan menimpa pelakunya. Allah taala berfirman :

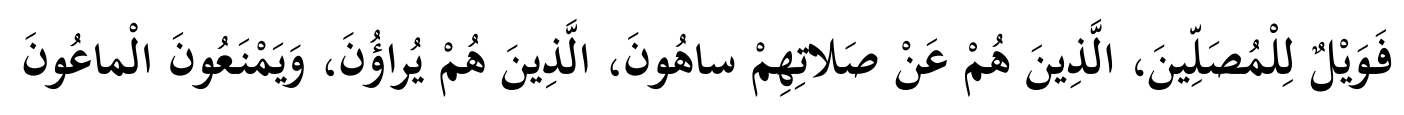

Maka celakalah bagi orang yang salat, yaitu orang-orang yang lalai dari salatnya, orang-orang yang berbuat riya dan mencegah dari menolong dengan barang yang berguna. (Qs. Al Ma'un : 4-7)

Riya membatalkan amalan sebagaimana Allah taala berfirman:

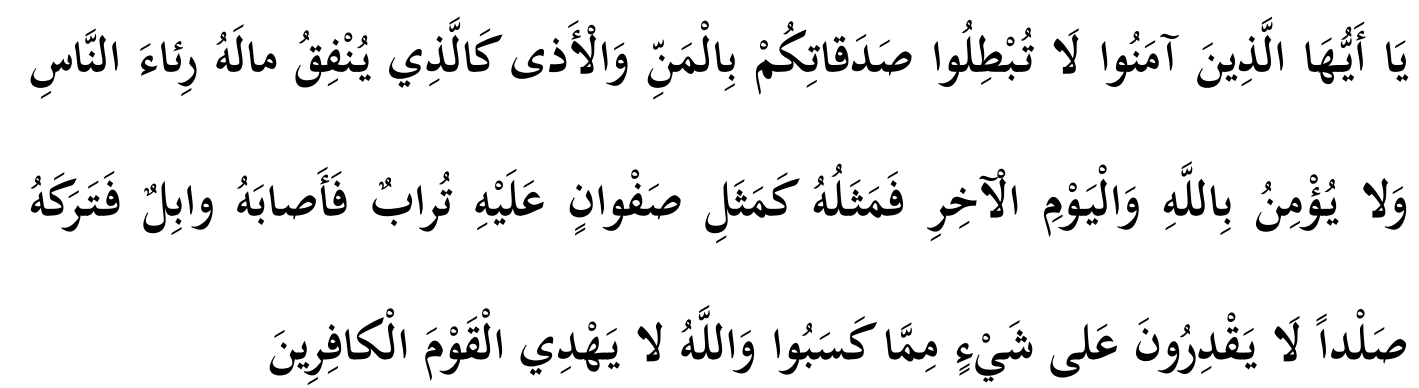

Hai orang-orang yang beriman, janganlah kalian menghilangkan pahala sedekah kalian dengan menyebut-nyebutnya dan menyakiti perasaan si penerima, 
seperti orang yang menginfakkan hartanya karena riya kepada manusia dan tidak beriman kepada Allah dan hari akhir. Maka perumpamaan orang itu seperti batu licin, di atasnya ada tanah, kemudian batu itu ditimpa hujan lebat, maka iapun bersih. Mereka tidak menguasai sesuatu pun dari apa yang mereka usahakan dan Allah tidak memberi petunujuk kepada orang-orang kafir. (Qs. Albaqarah : 264)

Pahala sedekah ibarat tanah atau debu yang ada pada batu licin, datanglah hujan, tanah itupun lenyap seketika. Jadi jelas bagi kita bahwa syirik dan riya membatalkan amal ibadah kita. Bedanya syirik membatalkan seluruh amalan kita dan pelakunya kekal dalam neraka jika belum bertobat, sedangkan riya membatalkan amalan yang ia riya padanya.

Kedua, makan harta haram.

Harta haram mempengaruhi diterima atau tidaknya amal ibadah kita, Rasulullah shalallahu alaihi wasallam bersabda :

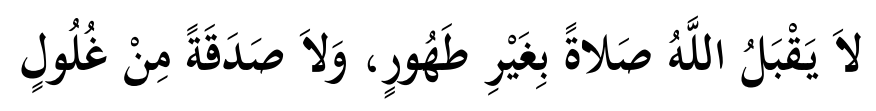

Allah tidak akan menerima salat seseorang tanpa bersuci dan tidak akan menerima sedekah dengan harta dari kecurangan. (HR. Muslim)

Umat Islam sangat senang bersedekah, mereka berinfak untuk masjid, bersedekah untuk fakir miskin dan sebagainya. Jika harta yang disedekahkan itu dari harta haram, maka semua sedekah itu tidak diterima Allah taala sebagaimana salat seoseorang tidak diterima tanpa bersuci.

Dalam hadis lain Rasulullah shalallahu alaihi wasallam bersabda tentang wajibnya makan dari harta halal dan pengaruhnya terhadap ibadah jika kita makan dari yang haram.

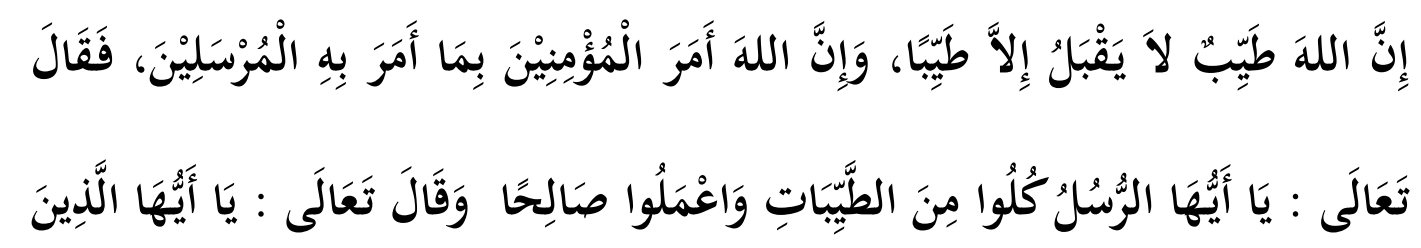




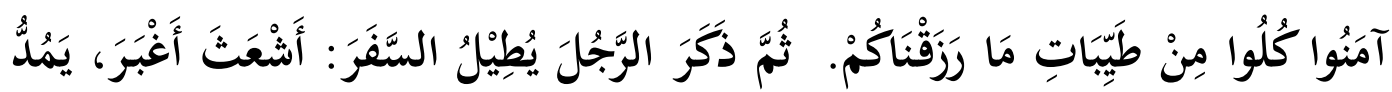

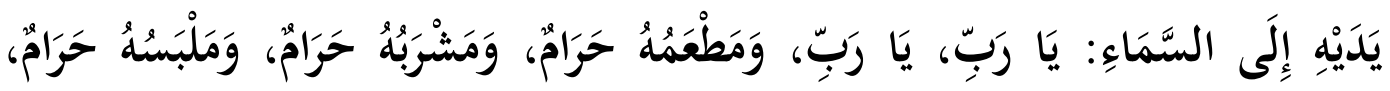

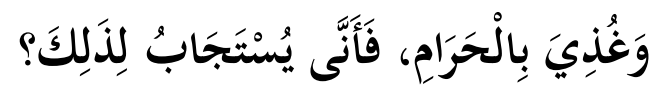

Sesungguhnya Allah itu baik dan tidak menerima kecuali yang baik pula. Sesungguhnya Allah memerintahkan kepada kaum mukminin seperti yang Dia perintahkan kepada para rasul. Allah berfirman "wahai para rasul, makanlah dari yang baik-baik dan kerjakanlah kebaikan” (Al-Mukminun:51) dan Allah berfirman "wahai orang-orang yang beriman, makanlah dari rizki yang baik yang Kami berikan kepadamu” (Albaqarah:172) kemudian Rasulullah menyebutkan seorang yang berada dalam perjalanan panjang, rambutnya kusut, berdebu,ia menengadahkan kedua tangannya ke langit "wahai Rabb-ku, wahai Rabb-ku” sedangkan makanannya haram, minumannya haram, pakaiannya haram dan tumbuh besar dengan harta haram, bagaimana doanya akan dikabulkan? (HR. Bukhari dan Muslim)

Pada hadis di atas ada beberapa poin penting yang mesti kita perhatikan :

Poin petama, Allah taala tidak menerima amalan kecuali yang baik, jika sedekah kita dari yang haram maka ia ditolak. Haram berarti buruk, sedangkan Allah taala hanya menerima yang baik saja.

Poin kedua, Allah taala memerintahkan kita makan dari yang baik atau halal kemudian diiringi dengan amal saleh atau kebajikan, maka dari sini kita paham bahwa ada kaitan antara makanan yang halal dengan amal saleh yang kita kerjakan.

Poin ketiga, lihatlah bagaimana doa seorang hamba ditolak karena harta haram yang ada pada dirinya dan doa adalah salah satu ibadah penting, padahal sebab dikabulkannya doa banyak terdapat padanya seperti dalam kedaan safar, keadaan lusuh atau kesusahan, mengangkat tangan, berwasilah dengan nama Allah taala dan mengulang-ngulangnya. Dalam hadis di atas disebutkan doanya 
ditolak karena makan harta haram, doa adalah ibadah, maka dapat kita pahami ibadah lainpun tidak diterima jika kita makan, berpakaian, berkendaraan, bertempat tinggal dengan yang haram.

Ketiga, berkata ucapan yang sia-sia, kusus puasa

Manusia adalah makhluk yang suka bicara, terkadang penting, terkadang tidak berguna, ada ucapan yang baik, ada pula yang buruk. Tidak dapat kita bayangkan betepa banyak kata yang diucapkan lidah kita dalam setiap hari yang kita jalani. Kita dilarang bicara hal yang tidak bermanfaat, terlebih saat puasa, Rasulullah shalallahu alaihi wasallam bersabda :

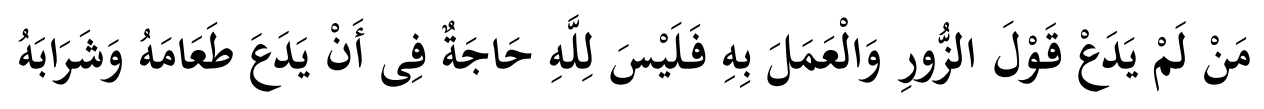

Siapa yang tidak meninggalkan perkataan dusta dan mengamalkannya, maka Allah tidak butuh ia meninggalkan makan dan minum karena puasa. (HR. Bukhari)

Qauluz zur adalah ucapan dusta dan bisa juga ucapan buruk dan sia-sia. Jika kita berkata dusta atau mengucapkan perkataan tercela, maka Allah taala tidak butuh atau tidak peduli apakah kita puasa atau tidak. Artinya pahala puasa kita tidak ada, walaupun puasa kita tidak batal.

Perumpamaannya seperti seorang guru yang memerintahkan muridnya untuk belajar sungguh-sungguh untuk ujian, saat belajar murid itu melakukan suatu kesalahan yang dianggap besar oleh guru tersebut, maka betapapun pintarnya anak itu dan berapapun benar jawabannya saat ujian tetap saja ia gagal, karena bagi guru tersebut kesalahan siswa itu membuat ia tidak memenuhi syarat untuk lulus. Maka guru itu berkata "saya tidak butuh kamu belajar sungguhsungguh atau tidak karena kesalahanmu itu”

Dan memang guru itu tidak butuh muridnya belajar atau tidak, tapi muridlah yang butuh belajar. Begitu pulalah Allah taala tidak butuh kita puasa, kitalah yang membutuhkan Allah taala, itulah sebabnya kita puasa. 
Keempat, berbuat bidah.

Selain hal di atas terdapat satu perbuatan yang membuat amalan tertolak yaitu berbuat bidah atau mengadakan amalan baru dalam agama, Rasulullah shalallahu alaihi wasallam bersabda :

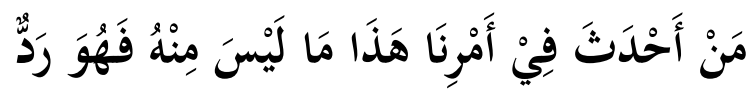

Siapa yang mengadakan ibadah dalam agama maka ia tertolak. (HR.

Bukhari dan Muslim)

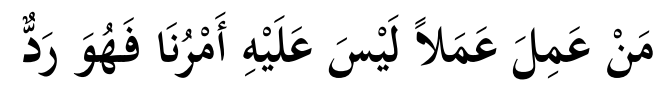

Siapa yang beramal dengan amalan yang tidak pernah kami lakukan

dalan agama, maka amalannya tertolak. (HR. Muslim)

Banyak ibadah yang tidak ada dasarnya dilakukan orang pada bulan Ramadan, maka marilah kita pelajari apakah ia berlandaskan petunjuk Nabi shalallahu alaihi wasallam atau tidak, agar amalan itu tidak sia-sia kita lakukan. Pintu surga dibuka pada bulan Ramadan, jaga ibadah dan perbuatan kita, utamakan ikhlas dan ketepatan ibadah dengan ilmu, agar tiket kita dapatkan untuk memasukinya.

Berbuat bidah bisa jadi karena tidak adanya ilmu, sehingga mereka mengira amalan yang mereka ada-adakan adalah sebuah kebaikan, mereka beramal dengan perasaan bukan dengan ilmu.

Sekian beberapa penjelasan singkat tentang jalan menunju diterimanya amalan kita oleh Allah taala, mari kita penuhi syarat pertama yaitu mengilmuinya serta menjauhi penyebab amalan itu ditolak oleh Allah taala. 
Daftar pustaka :

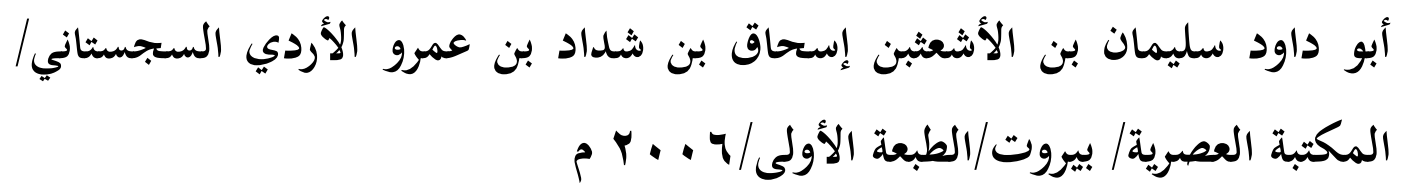

أبو عبد الله أحمد بن محمد بن حنبل بن هلال بن أسد الشيباني/مسند الإمام

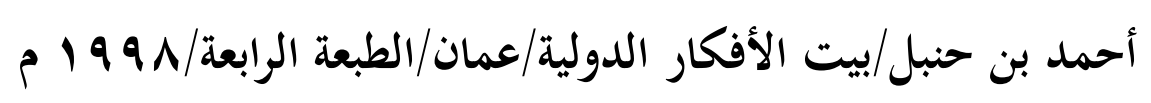

مسلم بن الحجاج أبو الحسن القشيري النيسابوري/المسند الصحيح المختصر بنقل العدل إلى رسول الله صلى الله عليه وسلم/ /دار الغد الجديد/القاهرة/الطبعة

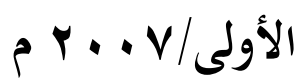

محمد بن إسماعيل أبو عبد الله البخاري/الجامع المسند الصحيح المختصر من

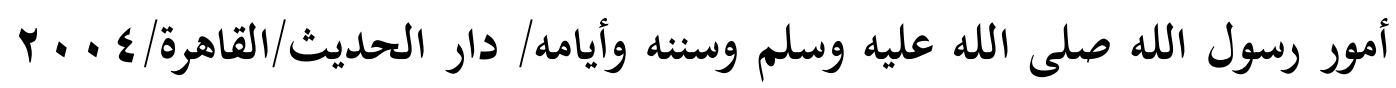


